\title{
Ideomotor apraxia without aphasia and aphasia without apraxia: the anatomical support for a double dissociation
}

\author{
Costanza Papagno, Sergio Della Sala, Anna Basso
}

\begin{abstract}
This study aimed to verify the existence of a double aphasia/apraxia dissociation. Apraxic patients without aphasia and aphasic patients without apraxia were included in a consecutive series of patients with cortical or subcortical CT documented vascular lesions in the left hemisphere. Of 699 patients, 10 were found to be apraxic but not aphasic and 149 aphasic but not apraxic. These findings indicate an aphasia/apraxia double dissociation. This suggests that praxis and language make use of two different, partly overlapping networks.
\end{abstract}

(F Neurol Neurosurg Psychiatry 1993;56:286-289)

The term "apraxia" encompasses various disorders affecting the purposeful execution of deliberate movements which cannot be explained by elementary motor-sensory deficits, perceptual and comprehension impairment or severe mental deterioration. ${ }^{1}$ Ideomotor apraxia is a form of apraxia in which the implementation of the gesture in a precise motor programme is disrupted. ${ }^{1}$ In right handed subjects ideomotor apraxia is associated with lesions in the left hemisphere ${ }^{23}$ which is also dominant for language and has therefore often been associated with aphasia. Ajuriaguerra et $a^{4}$ reported that $90 \%$ of patients with ideomotor apraxia also had aphasia. Conversely 32 of $60(53 \%)$ aphasic patients ${ }^{5}$ were also apraxic.

The association between aphasia and apraxia is often due to the encroachment of the lesion upon contiguous structures, differentially specialised for language and praxis. ${ }^{1}$ Aphasia has often been reported in the absence of apraxia ${ }^{5}$ which supports this theory. The opposite pattern (apraxia without aphasia) has rarely been reported.

Liepmann $^{6}$ (quoted by Ajuriaguerra et al ${ }^{4}$ ) reported 7 non-aphasic patients with poorly specified disturbances of praxis, 6 of whom had right hemiplegia and therefore presumably a left-hemisphere lesion. Recently, Goodglass and Kaplan ${ }^{7}$ reported 5 mildly apraxic though non-aphasic patients with left brain damage, Heilman et af reported a non-aphasic, right handed man who was examined three months after a left-hemisphere stroke who showed ideomotor apraxia and agraphia, and Selnes et $a l$ described a patient with transient fluent aphasia with an auditory comprehension deficit and persistent apraxia and dysgraphia three years after frontoparietal ischaemia. Selnes et $a l^{10}$ described an 81 year old right handed man, affected by myasthenia gravis who, one month after a massive left-hemisphere stroke, showed marked limb apraxia coupled with dyscalculia, right neglect, anosognosia, agraphia but no aphasia, except for mild dysnomia.

One apraxic patient out of 40 non-aphasic subjects with left brain damage was reported by De Renzi et al. ${ }^{5}$ Agostoni et al ${ }^{11}$ described a patient (case 5) who sustained an ischaemic lesion of the internal capsule and caudate nucleus, and was not aphasic. To find support for the notion of dissociability between aphasia and apraxia, Kertesz et $\mathrm{al}^{13}$ studied a series of 143 patients who had sustained a cortical or subcortical stroke of the left-hemisphere and who had been examined at least three months afterwards. In 2 severe and 7 moderate aphasic patients, praxis was spared and in one case of mild aphasia, praxis was moderate. Kertesz et $\mathrm{al}^{13}$ did not observe apraxia in non-aphasic patients. Junqué et al $^{14}$ reported a right handed patient who had ideomotor apraxia but not aphasia, after a massive left-hemisphere infarction. Recently Della Sala et $a l^{15}$ reported a patient (case 29) with apraxia and without aphasia in a series of patients with left hemisphere subcortical lesions.

In this study we aimed to verify the existence of a double dissociation between aphasia and apraxia. For this purpose we systematically searched for apraxic non-aphasic subjects and vice versa in a consecutive series of patients with cortical or subcortical left-hemisphere vascular lesions.

\section{Material and methods \\ Subjects}

Among the patients examined at the Aphasia Unit at Milan University between 1979 and 1988, we selected the 699 right handed patients with CT documented vascular lesion in the left-hemisphere (CT without enhancement performed at least 15 days after the stroke).

\section{Neuropsychological investigation}

All subjects had the following neuropsychological examination at different intervals after stroke:

1) Ideomotor apraxia

A 24 item test for ideomotor apraxia, which consists of half nonsymbolic and half symbolic movements, half requiring the holding of a static position and half the execution of motor 
Table 1 Apraxic non-aphasic subjects

\begin{tabular}{|c|c|c|c|c|c|c|c|c|}
\hline \multirow[b]{2}{*}{ Number } & \multirow[b]{2}{*}{ Age } & \multirow[b]{2}{*}{ Sex } & \multirow{2}{*}{$\begin{array}{l}\text { Education } \\
\text { (years) }\end{array}$} & \multicolumn{2}{|l|}{ Lesion site } & \multirow{2}{*}{$\begin{array}{l}\text { Interval Stroke- } \\
\text { Examination } \\
\text { (days) }\end{array}$} & \multirow{2}{*}{$\begin{array}{l}T T \\
(0-36) \\
\text { cut-of } \geqslant 29)\end{array}$} & \multirow{2}{*}{$\begin{array}{l}I M A \\
(0-72 \\
\text { cut-off>53) }\end{array}$} \\
\hline & & & & $L$ & $R$ & & & \\
\hline $\begin{array}{l}1 \\
2 \\
3^{\star} \\
4\end{array}$ & $\begin{array}{l}54 \\
60 \\
68 \\
39\end{array}$ & $\begin{array}{l}\mathbf{M} \\
\mathbf{M} \\
\mathbf{M} \\
\mathbf{M}\end{array}$ & $\begin{array}{r}7 \\
4 \\
17 \\
5\end{array}$ & $\begin{array}{l}\text { Fr-WM } \\
\text { P-WM } \\
\text { Fr-P-WM } \\
\text { Fr-WM } \\
\text { genu IC }\end{array}$ & Pcort-Subc. & $\begin{array}{r}61 \\
80 \\
14 \\
180\end{array}$ & $\begin{array}{l}30 \\
32 \\
29 \\
33\end{array}$ & $\begin{array}{l}52 \\
51 \\
51 \\
49\end{array}$ \\
\hline $\begin{array}{r}5 \\
6 \\
7 \\
8 \\
9 \\
10\end{array}$ & $\begin{array}{l}56 \\
77 \\
60 \\
63 \\
63 \\
59\end{array}$ & $\begin{array}{l}\mathbf{M} \\
\mathbf{M} \\
\mathbf{M} \\
\mathrm{F} \\
\mathbf{F} \\
\mathrm{F}\end{array}$ & $\begin{array}{r}13 \\
8 \\
7 \\
10 \\
8 \\
5\end{array}$ & $\begin{array}{l}\text { Fr-P-WM } \\
\text { T-WM } \\
\text { head NC } \\
\text { Fr-P-WM, T } \\
\text { Fr-P } \\
\text { head CN(I) } \\
\text { P (H) }\end{array}$ & $\begin{array}{l}\text { Fr-P-WM } \\
\text { WM }\end{array}$ & $\begin{array}{r}976 \\
30 \\
22 \\
34 \\
55 \\
30\end{array}$ & $\begin{array}{l}31 \\
29 \\
30 \\
34 \\
32 \\
29\end{array}$ & $\begin{array}{l}45 \\
42 \\
40 \\
43 \\
37 \\
36\end{array}$ \\
\hline
\end{tabular}

Key: $\mathrm{CN}=$ nucleus caudatus, $\mathrm{F}=$ female, $\mathrm{Fr}=$ frontal, $\mathrm{H}=$ haemorrhage, $\mathrm{I}=$ ischaemia, $\mathrm{IC}=$ internal capsule, $\mathrm{IMA}=$ ideomotor apraxia, $\mathrm{L}=$ left, $M=$ male, $\mathrm{O}=$ occipital, $\mathrm{P}=$ parietal, $\mathrm{R}=$ right, $\mathrm{T}=$ temporal, $\mathrm{TT}=$ Token Test, $\mathrm{WM}=$ white matter
${ }^{\prime}$ Case 29 in Della Sala et al $^{15}$

sequences, half to be performed with the whole hand, and half with the fingers only. The patient is asked to imitate the movement shown by the examiner with the hand ipsilateral to the lesion. Performance is scored, $3,2,1,0$, depending on whether it is correct on the first, second or third presentation or unsuccessful. The total ranges from a worst of 0 to a best of 72 . $^{5}$

\section{2) Language examination}

A test of language comprehension, the Token Test. The score ranges from 0 to $36 .{ }^{12} \mathrm{~A}$ complete standard language examination. ${ }^{16}$ This includes subtests of production, comprehension, repetition, writing and reading of both words and sentences. Scores are given as a percentage of correct responses.

\section{Procedure}

Double dissociation is a standard procedure in neuropsychology, ${ }^{17} 18$ which enables one to infer that there is a difference in the set of separable subsystems used by two functions. ${ }^{19}$ To avoid the bias of resource artefacts ${ }^{19}$ we decided to use a more stringent criteria than the above/below cut-off value separation. We selected patients with an ideomotor apraxia score less than 53, which was the worst score found in a group of 187 controls $^{20}$ and which corresponds to the $95 \%$ outer tolerance limit of the normal population. When these subjects had a TT score equal or greater than the cutoff $(=29) \quad(5 \%$ of the normal population is expected to fall below this number ${ }^{12}$ ) and had a normal language examination, ${ }^{16}$ we considered them to be apraxic and non-aphasic.

Table 2 Standard Language Examination scores of the apraxic non-aphasic patients $(n=10)$

\begin{tabular}{|c|c|c|c|c|c|c|c|c|c|c|}
\hline \multirow[b]{2}{*}{ Number } & \multicolumn{2}{|c|}{ Production } & \multicolumn{2}{|c|}{ Comprehension } & \multicolumn{2}{|c|}{ Repetition } & \multicolumn{2}{|c|}{ Writing } & \multicolumn{2}{|c|}{ Reading } \\
\hline & $\boldsymbol{W}$ & $s$ & $W$ & $S$ & $W$ & $s$ & $W$ & $s$ & $W$ & $S$ \\
\hline 1 & 95 & 50 & 100 & 100 & 100 & 100 & 100 & 100 & 90 & 100 \\
\hline 2 & 60 & 40 & 100 & 100 & 90 & 50 & 80 & 60 & 100 & 90 \\
\hline 3 & 90 & 70 & 100 & 100 & 100 & 100 & 100 & 100 & 100 & 100 \\
\hline 4 & 95 & 50 & 100 & 100 & 100 & 100 & 100 & 100 & 100 & 100 \\
\hline 5 & 95 & 50 & 100 & 90 & 100 & 100 & 95 & 80 & 100 & 100 \\
\hline 6 & 100 & 85 & 95 & 100 & 100 & 100 & - & - & 100 & 100 \\
\hline 7 & 100 & 50 & 100 & 100 & 100 & 100 & 100 & 100 & 100 & 100 \\
\hline 8 & 97 & 50 & 100 & 80 & 100 & 100 & 100 & 80 & 100 & 100 \\
\hline 9 & 100 & 90 & 100 & 80 & 100 & 100 & 80 & 30 & 100 & 100 \\
\hline 10 & 87 & 70 & 100 & 90 & 80 & 80 & 70 & 0 & 90 & 100 \\
\hline
\end{tabular}

Scores are marked out of a total of 100
We defined subjects as aphasic and nonapraxic subjects if they scored 24 or less on the Token Test. Only 2 out of 215 normal controls performed below this score which corresponds to De Renzi and Faglioni's ${ }^{12}$ definition of moderate or more severe aphasia. These subjects were also classified as moderate or more severely aphasic by the standard language examination $^{16}$ we employed. Their ideomotor apraxia test score was above 63 , the $95 \%$ inner tolerance limit (Faglioni, personal communication). For each test, we left a no-decision band. From this pattern we can identify a valid double dissociation ${ }^{19}$ to enable the inference of the possible existence of two separate subsystems. $^{21}$

\section{Results}

Apraxic non-aphasic subjects

Of 699 patients, 10 were apraxic but not aphasic as defined by our criteria (tables 1 and 2). Cases 6, 9 and 10 were dysgraphic, but their oral language did not show aphasic deficits.

In particular, case 6 had peripheral dysgraphia, with ill-formed letters and the addition of strokes and found the task so difficult that he refused to complete it, while case 10 , faced with the writing sentence task (to write a letter), failed to put pen to paper. Case 2 was dysarthric and it was therefore not always possible to fully understand his pronunciation: this explains why his scores on tasks of production and repetition were not normal: comprehension, however, was entirely normal.

The lesion involved also the right hemisphere in four cases. ${ }^{15710}$ Most subjects had ischaemic lesions only. Cases 2 and 4 had a subarachnoid haemorrhage, case 10 had an ischaemic and a haemorrhagic lesion in the left hemisphere and an ischaemic lesion in the right. Seven patients (cases 1 to 7 ) had lesions on CT scans localised only in subcortical structures: in all patients except case 7 , the white matter was involved (table 1). In the other three cases ( 8 to 10 ) the lesion also encroached upon the cortex. Ideomotor apraxia was mild to moderate in subcortical lesions (range 40-52, mean 47.1), and more severe (range 36-43, mean 38.7) in the cases with a cortical lesion. 
Aphasic non-apraxic subjects

According to our criteria (see procedures), 149 patients were aphasic (they scored 24 or less on the Token Test and were classified as moderately or more severely aphasic by a standard language examination), but not apraxic (ideomotor apraxia score equal to or higher than 63). Eighty four of these had a moderate Token Test impairment (score from 17 to 24 ) according to the classification by De Renzi and Faglioni, ${ }^{12} 47$ had a severe impairment (Token Test score from 9 to 16 ) and 18 had a very severe impairment (Token Test score from 0 to 8). Four patients of this latter group performed at ceiling on ideomotor apraxia.

Twenty of them had a subcortical lesion and 129 a cortical lesion, 12 of whom also had a right-hemisphere lesion. In the group of patients with subcortical lesion, 4 had a lesion involving the white matter only and 1 only the grey nuclei. In the remaining 15 cases the lesions involved both white matter and grey nuclei.

These data fulfil Shallice's ${ }^{19}$ criteria for a valid double dissociation as all the patients in the first group (apraxic and non-aphasic) performed language tests better than ideomotor apraxia and in all cases better than all subjects of the second group (that is, aphasic and non-apraxic). On the contrary all subjects of the second group obtained a higher ideomotor apraxia score than their Token Test score, which was also higher than all subjects in the first group. Furthermore, they all proved to be aphasic on a standard language examination.

\section{Discussion}

Apraxia is common in clinical practice in association with aphasia but very seldom seen in isolation. It is well known that aphasia can be found without apraxia, ${ }^{513}$ and our data confirm these findings. Some of the dissociations in performances were very striking in our patient group: 4 of 18 patients with very severe aphasia performed at the top of the score in the ideomotor apraxia test. In this study we also looked for the opposite pattern, that is, apraxia without aphasia. This second pattern (apraxia without aphasia) was less common, but this could partly be due to the fact that the patients we examined were referred to us mainly because of language problems. In accordance with our criteria we demonstrated a double dissociation between aphasia and apraxia in patients with left-hemisphere damage.

In the present investigation 7 non-aphasic apraxics out of 10 had a subcortical lesion. Only 20 of our 129 aphasic non-apraxic patients had subcortical lesions.

The cases reported here confirm the role of white matter in the occurrence of ideomotor apraxia in subcortical lesions, ${ }^{1522}$ as opposed to grey nuclei. In the present series, the basal ganglia were involved alone in one apraxic case only (case 7), with a single lesion in the head of the left caudate nucleus. In this case, however, it is difficult to exclude involvement of the superior occipito-frontal fasciculus, said to be important for imitating gestures, ${ }^{2324}$ which lies immediately above the head of the caudate nucleus.

Conversely, among the 20 aphasic patients without apraxia and with a subcortical lesion, only four had damage confined to the white matter. In deep lesions, aphasia was mainly due to basal ganglia and thalamus involvement, and no symptoms occurred if the white matter alone is damaged. ${ }^{25}$ The reverse pattern seems to be true for ideomotor apraxia. ${ }^{15}$

The subcortical WM/nuclei dissociation simply suggests that the anatomical sites for praxis and language are separate and that these two functions may employ two different partly overlapping networks of the type suggested by Mesulam for attention. ${ }^{26}$ This suggestion is indirectly supported by two observations. Firstly, the correlation between the severity of the two disorders is low. ${ }^{13}$ Secondly, the dissociation is also encountered in mild Alzheimer's disease in which ideomotor apraxia is less common and severe than aphasia. ${ }^{27}$ In our series there were 4 patients who were aphasic and not apraxic with a white matter lesion only. The long time interval between development of the lesion and the time of examination could be the cause of this unexpected result. ${ }^{252930}$ All our patients with a white matter lesion were tested approximately 30 days after the stroke. Two patients improved sufficiently to reach a normal language level in a second examination. If aphasia is present in a white matter lesion, it is usually mild and recovery is generally the rule.

Bihemispheric representation of praxis was used to explain the discrepancy between persistence of aphasia and recovery from apraxia. ${ }^{13}$ This idea is not supported by our observation that 6 of 10 apraxic non-aphasic patients had a single lesion. The bihemispheric representation of functions has also been proposed post hoc in the opposite direction: Selnes et $a l^{9}$ proposed (for their case of apraxia with transient aphasia) a bilateral representation of language but unilateral kinesthetic motor engrams or a case of mixed dominance. Junqué et $a^{13}$ suggested that ideomotor praxis is the only function that does not follow a crossed representation, because their right handed patient with a left-hemisphere infarct had neuropsychological disturbances compatible with a right-hemisphere lesion, apart from ideomotor apraxia. In crossed aphasia the lesion is in the hemisphere ipsilateral to the preferred hand. Selnes et al ${ }^{10}$ claimed that right handed patients affected by crossed aphasia, whose lesion is in the right hemisphere, do not show limb apraxia. However, Castro-Caldas et al $^{31}$ found 10 of the 52 cases (19\%) with crossed aphasia who performed pathologically on ideomotor praxis tests.

In conclusion, our data indicate an aphasiaapraxia double dissociation suggesting that praxis and language use two different, partly overlapping, networks.

1 De Renzi E. Apraxia. In: Boller F, Grafman J, eds. Handbook of neuropsychology, vol 2. Amsterdam: Elsevier 1989:
245-63. 
2 Heilman KM, Gonzalez-Rothi LJ. Apraxia. In: Heilman $\mathrm{KM}$ and Valenstein E, eds. Clinical neuropsychology Oxford, Oxford University Press, 1985:131-49.

3 Faglioni P, Basso A. Historical perspectives on neuroanatomical correlates of limb apraxia. In: Roy EA, ed. Neuropsychological study of apraxia and related disorders. Amsterdam, North Holland, 1985:3-44.

4 Ajuriaguerra J, Hécaen $\mathrm{H}$, Angelergues R. Les apraxies: variétés cliniques et lateralisation lésionnelle. Rev Neurol 1960;102:566-94.

5 De Renzi E, Motti F, Nichelli P. Imitating gestures: a quantitative ap

6 Liepmann H. Die linke Hemisphere und das Handeln. Münchener Medizinische Wochenschrift 1905;49:2322-6.

7 Goodglass H, Kaplan E. Disturbances of gesture and Goodglass H, Kaplan E. Disturbances of ges

8 Heilman KH, Goneya EF, Geschwind N. Apraxia and agraphia in a right hander. Cortex 1974;10:284-8.

9 Selnes OA, Rubens AB, Risse GL, Levy RS. Transient aphasia with persistent apraxia. Uncommon sequela of massive left-hemisphere stroke. Arch Neurol 1982; 39:122-6.

10 Selnes OA, Pestronk A, Hart J, Gordon B. Limb apraxia without aphasia from a left sided lesion in a right hande patient. I Neurol Neurosurg Psychiatry 1991;54:734-7.

11 Agostoni E, Coletti A, Orlando G. Tredici G. Apraxia in deep cerebral lesions. $\mathcal{f}$ Neurol Neurosurg Psychiatry 1983;46:804-8.

12 De Renzi E, Faglioni P. Normative data and screening power of a shortened version of the Token Test. Cortex power of a short
$1978 ; 414: 41-9$.

13 Kertesz A, Ferro JU, Shewan CM. Apraxia and aphasia: the functional anatomical basis for their dissociation. Neurol functional ana

14 Junqué C, Litvan I, Venderell P. Does reversed laterality really exist in dextrals? A case study. Neuropsychologia $1986 ; 24: 241-54$

15 Della Sala S, Basso A, Laiacona M, Papagno C. Subcortical localisation of ideomotor apraxia: a review and an experimental study. In: Cappa SF, Vallar G, Wallesch KW, eds. Neuropsychological disorders associated with subcortical

16 Basso A, Capitani E, Vignolo LA. Influence of rehabilitation on language skills in aphasic patients. A controlled study. Arch Neurol 1979;36:190-6.

17 Teuber HL. Physiological psychology. Ann Rev Psychol 1955;9:267-96.

18 Kinsbourne $M$. Cognitive deficit: experimental analysis. In: McGaugh JL, ed. Psychobiology. New York, Academic Press, 1971 .

19 Shallice T. From Neuropsychology to Mental Structure. Cambridge, Cambridge University Press, 1988.

20 De Renzi E, Faglioni P, Scarpa M, Crisi G. Limb apraxia in patients with damage confined to the left basal ganglia and thalamus. F Neurol Neurosurg Psychiatry 1986;49. $1030-8$.

21 Sartorii $G$. From neuropsychological data to theory and vice versa. In: Denes G, Bisiqochi P, Semenza C, Andreewsky E, eds. Perspective in Cognitive Neuropsychology. London: Erlbaum, 1988 .

22 Kertesz A, Ferro JM. Lesion size and location in ideomotor apraxia. Brain 1984;107:921-33.

23 Pandya DN, Kuypers HGJM. Cortico-cortical connections in the rhesus monkey. Brain Res 1969;13:13-36.

24 Jones EG, Powell TPS. An anatomical study of converging sensory pathways within the cerebral cortex of the monkey. Brain 1970;93:793-820

25 Wallesch C-W, Kornhuber HH, Brunner RJ, Kunz T, Hollerbach B, Suger G. Lesions of the basal ganglia, thalamus and deep white matter: differential effects on language functions. Brain and Lang 1983;20:286-303.

26 Mesulam MM. A cortical network for directed attention and unilateral neglect. Ann Neurol 1981;10:309-25.

27 Spinnler H, Della Sala S. The role of clinical neuropsychology in the neurological diagnosis of Alzheimer's disease. $f$ Neurol 1988;235:258-271.

28 Della Sala S, Lucchelli F, Spinnler H. Ideomotor apraxia in patients with dementia of Alzheimer type. $\mathcal{f}$ Neurol 987;234:91-3.

29 Basso A, Della Sala S, Farabola M. Aphasia arising from purely deep lesions. Cortex 1987;23:29-44

30 Puel M, Demonet JF, Cardebat D, Bonafe A, Gazounaud Y, Giraud-Chaumeil B, Rascol A. Aphasies sous-corticales. Rer Neurol 1984;140:695-710

31 Castro-Caldas A, Confraria A, Poppe P. Non-verbal disturbances in crossed aphasia. Aphasiology 1987;1: 403-13. 